\title{
High-carbohydrate-low-glycaemic index dietary advice improves glucose disposition index in subjects with impaired glucose tolerance
}

\author{
Thomas M. S. Wolever* and Christine Mehling \\ Department of Nutritional Sciences, Faculty of Medicine, University of Toronto, Toronto, Canada M5S 3E2 and Division of \\ Endocrinology and Metabolism, St. Michael's Hospital, Toronto, Ontario, Canada
}

(Received 5 June 2001 - Revised 26 November 2001 - Accepted 20 January 2002)

\begin{abstract}
Controversy exists about the optimal amount and source of dietary carbohydrate for managing insulin resistance. Therefore, we compared the effects on insulin sensitivity $\left(\mathrm{S}_{\mathrm{I}}\right)$, pancreatic responsivity $\left(\mathrm{AIR}_{\mathrm{glu}}\right)$ and glucose disposition index $\left(\mathrm{DI}=\mathrm{S}_{\mathrm{I}} \times \mathrm{AIR}_{\mathrm{glu}}\right)$ of dietary advice aimed at reducing the amount or altering the source of dietary carbohydrate in subjects with impaired glucose tolerance (IGT). Subjects were randomized to high-carbohydrate-high-glycaemic index (GI) (high-GI, $n$ 11), high-carbohydrate-low-GI (low-GI, $n$ 13), or low-carbohydrate-high-monounsaturated fat (MUFA, $n$ 11) dietary advice, with $\mathrm{S}_{\mathrm{I}}$, AIR glu and DI measured using a frequently sampled, intravenous glucose tolerance test before and after 4 months treatment. Carbohydrate and fat intakes and diet GI, respectively, were: high-GI, $53 \%, 28 \%, 83$; low-GI, $55 \%, 25 \%, 76$; MUFA, $47 \%, 35 \%, 82$. Weight changes on each diet differed significantly from each other: high-GI, -0.49 (SEM 0.29) kg; low-GI, -0.19 (SEM 0.40) kg; MUFA +0.27 (SEM 0.45) kg. Blood lipids did not change, but glycated haemoglobin increased significantly on MUFA, 0.02 (SEM 0.11) \%, relative to low-GI, -0.19 (SEM 0.08 ) $\%$, and high-GI, -0.13 (SEM 0.14) $\%$. Diastolic blood pressure fell by $8 \mathrm{mmHg}$ on low-GI relative to MUFA $(P=0.038)$. Although $S_{I}$ and $A_{\text {II }}$ glu did not change significantly, $\mathrm{DI}$, a measure of the ability of $\beta$-cells to overcome insulin resistance by increasing insulin secretion, increased on low-GI by $>50 \%(P=0.02)$. After adjusting for baseline values, the increase in DI on low-GI, 0.17 (SEM 0.07), was significantly greater than those on MUFA, -0.09 (SEM 0.08) and high-GI, -0.03 (SEM 0.02) $(P=0.019)$. Thus, the long-term effects of altering the source of dietary carbohydrate differ from those of altering the amount. High-carbohydrate-low-GI dietary advice improved $\beta$-cell function in subjects with IGT, and may, therefore, be useful in the management of IGT.
\end{abstract}

Dietary carbohydrates: Insulin sensitivity: Insulin secretion: Clinical trial

Over the past 20-25 years, high-carbohydrate, low-fat diets have been recommended for the general public (US Department of Agriculture, 1990; Food and Agricultural Organization of the United Nations, 1998). This advice is challenged by recent data showing that, compared with diets high in monounsaturated fat, high-carbohydrate diets raise plasma glucose, insulin and triacylglycerol and reduce HDL-cholesterol (Garg et al. 1994; Jeppesen et al. 1997), factors associated with atherosclerosis (Stout, 1990) and CHD (Balkau et al. 1998; Gordon \& Rifkind, 1989; Hokanson \& Austin, 1996). Furthermore, a high-carbohydrate diet raised plasma insulin to the greatest extent in people with insulin resistance (Jeppesen et al. 1997), which itself is associated with increased risk of obesity, cardiovascular disease, diabetes, and hypertension (Reaven, 1995). Thus it has been suggested that, since high-carbohydrate diets exacerbate the metabolic abnormalities of insulin resistance, they are deleterious for treating insulin resistance (Reaven, 1997).

However, not only are there few data on the effect of high-carbohydrate $v$. high-monounsatuated fat diets in insulin-resistant, non-diabetic subjects, but also few studies comparing the effects of low- and high-carbohydrate diets have taken into account the source of dietary carbohydrate

\footnotetext{
Abbreviations: AIR glu, pancreatic responsivity; DI, glucose disposition index; FSIGTT, frequently sampled intravenous glucose tolerance test; FSD, fractional standard deviation; GI, glycaemic index; $\mathrm{HbA}_{1 \mathrm{c}}$, glycated haemoglobin; high-GI, high-carbohydrate-high glycaemic index diet; IGT, impaired glucose tolerance; low-GI, high-carbohydrate-low-glycaemic index diet; MUFA, low-carbohydrate-high monounsatuated fat diet; NEFA, non-esterified fatty acids; $S_{I}$, insulin sensitivity.

* Corresponding author: Dr Thomas M. S. Wolever, fax +1 416978 5882, email thomas.wolever@utoronto.ca
} 
(Luscombe et al. 1999). Different carbohydrate foods are digested in vitro at different rates (Jenkins et al. 1982), which, in turn, are directly related to the blood glucose and insulin responses they elicit (Wolever et al. 1988). The glycaemic responses of foods are classified using the glycaemic index (GI) (Wolever et al. 1991). The incorporation of low-GI foods into mixed meals reduces glucose and insulin responses in normal (Chew et al. 1988) and diabetic subjects (Indar-Brown et al. 1992). Also, low-GI and high carbohydrate meals reduce postprandial nonesterified fatty acid (NEFA) concentrations (Wolever et al. 1995), which, in turn, may improve insulin secretion (Zhou \& Grill, 1994; Carpentier et al. 1999) and insulin action (Boden et al. 1994). Since the pathogenesis of type 2 diabetes involves defects in insulin action and insulin secretion (Ferrannini, 1998; Gerich, 1998), consideration of both insulin secretion and insulin sensitivity is important for those at risk of type 2 diabetes.

Since there is controversy about the optimal source and amount of carbohydrate for the management of insulin resistance, we compared the effects of altering the source of dietary carbohydrate with those of altering the amount of carbohydrate on insulin secretion and insulin sensitivity in subjects with impaired glucose tolerance (IGT). Reducing diet GI and reducing carbohydrate intake can have similar acute effects on reducing postprandial glucose and insulin responses. However, we hypothesized that these dietary manoeuvres would have different effects on insulin sensitivity and secretion in subjects with IGT.

\section{Methods}

A total of 257 subjects with at least one risk factor for diabetes (obesity, family history of diabetes, previous gestational diabetes, previous high blood glucose or triacylglycerol) were screened with a $75 \mathrm{~g}$ oral glucose tolerance test. Male and non-pregnant females with IGT, aged $30-65$ years, with BMI $<40 \mathrm{~kg} / \mathrm{m}^{2}$ and serum triacylglycerol $<10 \mathrm{mmol} / \mathrm{l}$ were eligible. Thiazide diuretics were used by one MUFA and one high-GI subject and a betablocker by one low-GI subject at stable doses throughout the study. IGT was defined as fasting plasma glucose $<7.8 \mathrm{mmol} / \mathrm{l}$ and plasma glucose $2 \mathrm{~h}$ after $75 \mathrm{~g}$ oral glucose $\geq 7.8 \mathrm{mmol} / \mathrm{l}$ and $<11.1 \mathrm{mmol} / \mathrm{l}$ (World Health Organization, 1980). Diagnostic criteria for diabetes changed after recruitment started (American Diabetes Association, 1997). Of the forty-four subjects identified as having IGT, thirty-seven $(84 \%)$ had normal fasting plasma glucose $(<6.1 \mathrm{mmol} / \mathrm{l})$, six had impaired fasting glucose $(6 \cdot 1-6.9 \mathrm{mmol} / \mathrm{l})$ and one, with fasting plasma glucose of $7.0 \mathrm{mmol} / \mathrm{l}$, would now be considered to have diabetes.

After baseline data were collected, subjects were randomized to one of three diets for 4 months: high-carbohydrate-high-GI (high-GI), high-carbohydrate-low-GI (low-GI), or low-carbohydrate-high-MUFA (MUFA). During the baseline period two 3-d food records were used as a basis for individualized dietary advice. Diets were prescribed on an ad-libitum basis. The aim was for the diets to be weight-maintaining, with the high-carbohydrate diets containing $55 \%$ of energy from carbohydrate and $30 \%$ from fat, and the MUFA diet $45 \%$ carbohydrate and $40 \%$ fat of which half was monounsaturated fat. Subjects on the high- or low-GI diets, respectively, were asked to have at least one serving of a high- or low-GI food at each meal. Lists of high- or low-GI foods were provided to subjects, along with specific food products to be used in the diet. Examples of high-GI foods provided included breakfast cereal, polished rice, instant potato and instant soups. Low-GI foods included breakfast cereal, bread, pasta, barley, parboiled rice, legumes and instant soups. Subjects on the MUFA diet were given supplements of olive oil and margarine made from non-hydrogenated rapeseed oil. Subjects were seen monthly for fasting blood samples, weight measurement, consultation with the dietitian and to hand in 3-d diet records and pick up study foods.

Insulin sensitivity $\left(\mathrm{S}_{\mathrm{I}}\right)$, glucose effectiveness, pancreatic responsivity (calculated as the area under the insulin response curve for $10 \mathrm{~min}$ after intravenous glucose; $\left.\mathrm{AIR}_{\mathrm{glu}}\right)$ and glucose disposition index $\left(\mathrm{DI}=\mathrm{S}_{\mathrm{I}} \times \mathrm{AIR}_{\mathrm{glu}}\right)$ were assessed by the frequently sampled intravenous glucose tolerance test (FSIGTT) (Finegood et al. 1990) at baseline and 4 months. After fasting blood samples at $-20,-10$ and $-5 \mathrm{~min}, 50 \%$ glucose solution $(25.1 \mathrm{ml} /$ $\mathrm{m}^{2}$ of body surface area) was rapidly injected at time 0 min and further blood samples taken at 2, 3, 4, 6, 8, $10,12,14,16$ and $19 \mathrm{~min}$. At $20 \mathrm{~min}$, insulin $\left(1.6 \mathrm{U} / \mathrm{m}^{2}\right)$ was injected and blood samples obtained at 22, 23, 24, $25,27,30,40,50,60,70,80,100,120,140,160,180$, 200, 220 and $240 \mathrm{~min}$. Plasma glucose and insulin results were analysed using the MINMOD computer program (Pacini \& Bergman, 1986).

Fasting total cholesterol and triacylglycerol were measured using a Vitros Analyser 950 (Johnson \& Johnson Clinical Diagnostics, Rochester, NY) with HDL-cholesterol measured after precipitation of other lipoproteins with dextran sulfate and magnesium chloride. LDL-cholesterol was calculated as total cholesterol - (HDL + triacylglycerols/2.2) (only for triacylglycerol $<4.51 \mathrm{mmol} / \mathrm{l}$ ). Glycated haemoglobin $\left(\mathrm{HbA}_{1 \mathrm{c}}\right)$ was measured by Diamat HPLC (Bio-Rad Laboratories (Canada) Ltd., Mississauga, Ontario, Canada). Fasting lipids and $\mathrm{HbA}_{1 \mathrm{c}}$ were measured at monthly intervals. Fasting plasma NEFA were measured at baseline and 4 months using a commercial kit (NEFA C, ACS-ACOD Method; WAKO Chemicals USA, Richmond, $\mathrm{VA}$ ).

Of forty-four eligible subjects, seven declined, and thirty-seven were randomized by coin toss, with stratification for age, gender and BMI, to receive one of the three test diets. Two high-GI and one MUFA subjects dropped out before the study ended. One subject participated in two arms of the study (MUFA and high-GI). For comparison with baseline data from IGT subjects, eight lean and seven obese normal controls underwent the FSIGTT.

The number of subjects studied was based on two considerations. The intra-individual variation of $\mathrm{S}_{\mathrm{I}}$ in healthy young subjects has been reported to have a CV of $14.4 \%$ (Ferrari et al. 1991). Using this CV, with twelve subjects in each group, there would be $90 \%$ power to detect a difference in $\mathrm{S}_{\mathrm{I}}$ of $20 \%$ (StatMate version 1.01; Graph Pad software, San Diego, CA). Using a different method to measure insulin sensitivity, we found that acarbose 
significantly improved insulin sensitivity by $17 \%$ in a parallel design study involving a total of only eighteen subjects with IGT (Chiasson et al. 1996).

Data are presented as means and standard errors of the mean. Baseline data for outcome variables were subjected to one-way ANOVA to determine if differences between groups existed. When no significant main effects were found, changes from baseline were subjected to one-way ANOVA. For post-hoc comparisons of individual means, the Newman-Keuls method was used to adjust for multiple comparisons. Adjustment for baseline values was performed by adding the residuals of the linear regression of change on baseline value to the mean change. Dietary intake data were subjected to ANOVA examining for main effects of diet and time and diet $\times$ time interaction. Values for glycaemic load were calculated by multiplying the diet GI by carbohydrate (g) and adjusting the resulting values for recorded energy intake (Salmerón et al. 1997b). $P \leq 0.05$ (2-tailed) was taken as statistically significant.

Procedures were reviewed and approved by the St. Michael's Hospital Research Ethics Board, and all subjects gave informed consent.

\section{Results}

Characteristics of IGT and control subjects are shown in Table 1. IGT and obese control subjects were of similar age and BMI, but were significantly older and more obese than lean controls. Generally, metabolic parameters were significantly impaired in IGT subjects relative to lean controls, with obese control values being intermediate. There was no difference between IGT and control subjects for serum lipids and NEFA. $S_{I}$ and AIR $_{\text {glu }}$ were significantly lower in IGT subjects than lean controls, with values for obese controls being intermediate (Table 1, Fig. 1(a)). DI was the only variable for which IGT, lean and obese control subjects differed significantly from each other. There was no significant difference in any parameter at baseline among the groups of IGT subjects randomized to the high-GI, low-GI or MUFA diets (Table 2, serum lipids and NEFA not shown).

Recorded energy intake during the study fell by about $690 \mathrm{~kJ}$ on low-GI, increased by about $880 \mathrm{~kJ}$ on MUFA and did not change on high-GI (diet $\times$ time interaction, $P=0.03$, Table 3). Subjects on MUFA recorded about 7 and $5 \%$ less carbohydrate and about 8 and $11 \%$ more total fat intake than those on low- and high-GI, respectively $(P<0 \cdot 05)$. The differences in total fat were accounted for by differences in monounsaturated fat. Subjects on lowGI recorded about $13 \mathrm{~g} / \mathrm{d}$ more dietary fibre and lower diet GI than those on the other two diets. Glycaemic load was significantly lower on MUFA than high-GI, with the value on low-GI being intermediate. The percentage of total energy contributed by various food groups before and during the dietary treatments is shown in Fig. 2. On high-GI, subjects increased their intake of high-GI starchy foods by $8 \%$ of energy, with about a $4 \%$ reduction in lowGI starchy foods and smaller reductions in fats, oils, nuts and mixed dishes. On the low-GI diet, there were small $(<2 \%$ energy) changes in intake of foods from several food groups; the main changes were an increased intake of low-GI starch (11\%) and low-GI soups (3\%) and a reduced intake of high-GI starch (8\%). On the MUFA diet, subjects increased intake of fats, oils and nuts by about $9 \%$ of energy and reduced intake of dairy foods by $4 \%$, with smaller reductions in high-GI starch, meats, and fruits and vegetables.

Mean body weight changes were very small, but there was a significant main effect of diet (Fig. 3(a)). Body weight tended to decrease on high-GI and low-GI and to increase on MUFA. The mean fall in body weight over weeks 4-16 on high-GI, - 0.49 (SEM 0.29) kg, was significantly greater than that on low-GI, -0.19 (SEM 0.40) kg, which, in turn, was significantly different from the small

Table 1. Comparison of control and impaired glucose tolerance (IGT) subjects at baseline

(Mean values and standard errors of the mean)

\begin{tabular}{|c|c|c|c|c|c|c|c|}
\hline & \multicolumn{2}{|c|}{ IGT } & \multicolumn{2}{|c|}{ Obese control } & \multicolumn{2}{|c|}{ Lean control } & \multirow[b]{2}{*}{$P^{*}$} \\
\hline & Mean & SEM & Mean & SEM & Mean & SEM & \\
\hline$n:$ Total & \multirow{2}{*}{\multicolumn{2}{|c|}{$\begin{array}{c}34 \\
7: 27\end{array}$}} & \multicolumn{2}{|c|}{7} & \multicolumn{2}{|c|}{8} & NS \\
\hline Men:women & & & & & & & NS \\
\hline Age (years) & $55 \cdot 6^{\mathrm{a}}$ & $2 \cdot 1$ & $58 \cdot 7^{\mathrm{a}}$ & $5 \cdot 8$ & $32 \cdot 4^{\mathrm{b}}$ & $4 \cdot 1$ & $<0.001$ \\
\hline BMI $\left(\mathrm{kg} / \mathrm{m}^{2}\right)$ & $30 \cdot 9^{\mathrm{a}}$ & 1.0 & $29 \cdot 3^{a}$ & 0.8 & $22.9^{b}$ & 0.9 & 0.003 \\
\hline Fasting glucose $(\mathrm{mmol} / \mathrm{l})$ & $5 \cdot 20^{\mathrm{a}}$ & 0.15 & $4.89^{a}$ & 0.29 & $4.04^{b}$ & 0.12 & 0.003 \\
\hline Glycated haemoglobin (\%) & $5.67^{\mathrm{a}}$ & 0.12 & $5 \cdot 20^{a b}$ & 0.18 & $4.74^{\mathrm{b}}$ & 0.16 & 0.002 \\
\hline NEFA $(\mathrm{mEq} / \mathrm{l})$ & 0.54 & 0.04 & 0.45 & 0.04 & 0.41 & 0.09 & NS \\
\hline Cholesterol $(\mathrm{mmol} / \mathrm{l})$ & $5 \cdot 24$ & 0.16 & $5 \cdot 33$ & 0.35 & 4.51 & 0.25 & NS \\
\hline Triacylglycerol (mmol/l) & 1.87 & 0.14 & 2.04 & 0.42 & $1 \cdot 10$ & 0.27 & NS \\
\hline HDL-cholesterol $(\mathrm{mmol} / \mathrm{l})$ & $1 \cdot 21$ & 0.06 & 1.33 & 0.16 & 1.56 & 0.21 & NS \\
\hline LDL-cholesterol (mmol//) & 3.18 & 0.13 & 3.08 & 0.29 & 2.45 & 0.27 & NS \\
\hline $\mathrm{S}_{1}\left(10^{-5} /(\mathrm{min} \times \mathrm{pmol} / \mathrm{l})\right)$ & $5 \cdot 17^{\mathrm{a}}$ & 0.51 & $7 \cdot 39^{a}$ & 1.36 & $13 \cdot 20^{\mathrm{b}}$ & 2.55 & $<0.001$ \\
\hline $\mathrm{S}_{\mathrm{G}}\left(10^{-2} / \mathrm{min}\right)$ & $1 \cdot 7$ & 0.1 & $4 \cdot 2$ & 2.7 & 2.5 & 0.4 & NS \\
\hline $\operatorname{AIR}_{\mathrm{glu}}\left(10^{2} \times \mathrm{pmol} / \mathrm{I} \times 10 \mathrm{~min}\right)$ & $6 \cdot 89^{a}$ & $1 \cdot 18$ & $9.79^{\mathrm{ab}}$ & 2.64 & $14 \cdot 14^{\mathrm{b}}$ & 1.74 & 0.026 \\
\hline DI $(/ 10)$ & $0.32^{a}$ & 0.06 & $0 \cdot 84^{b}$ & 0.39 & $1 \cdot 70^{c}$ & 0.30 & $<0.001$ \\
\hline
\end{tabular}

NEFA, non-esterified fatty acids; $S_{\text {I }}$, Insulin sensitivity index; $S_{G}$, glucose effectiveness; AIR glu $_{\text {, pancreatic responsivity }}$ (area under the insulin response curve for $10 \mathrm{~min}$ after intravenous glucose); DI, glucose disposition index.

a,b,c Mean values within a row with unlike superscript letters were significantly different $(P<0.05)$.

*Significance of $F$ value from one-way ANOVA. 

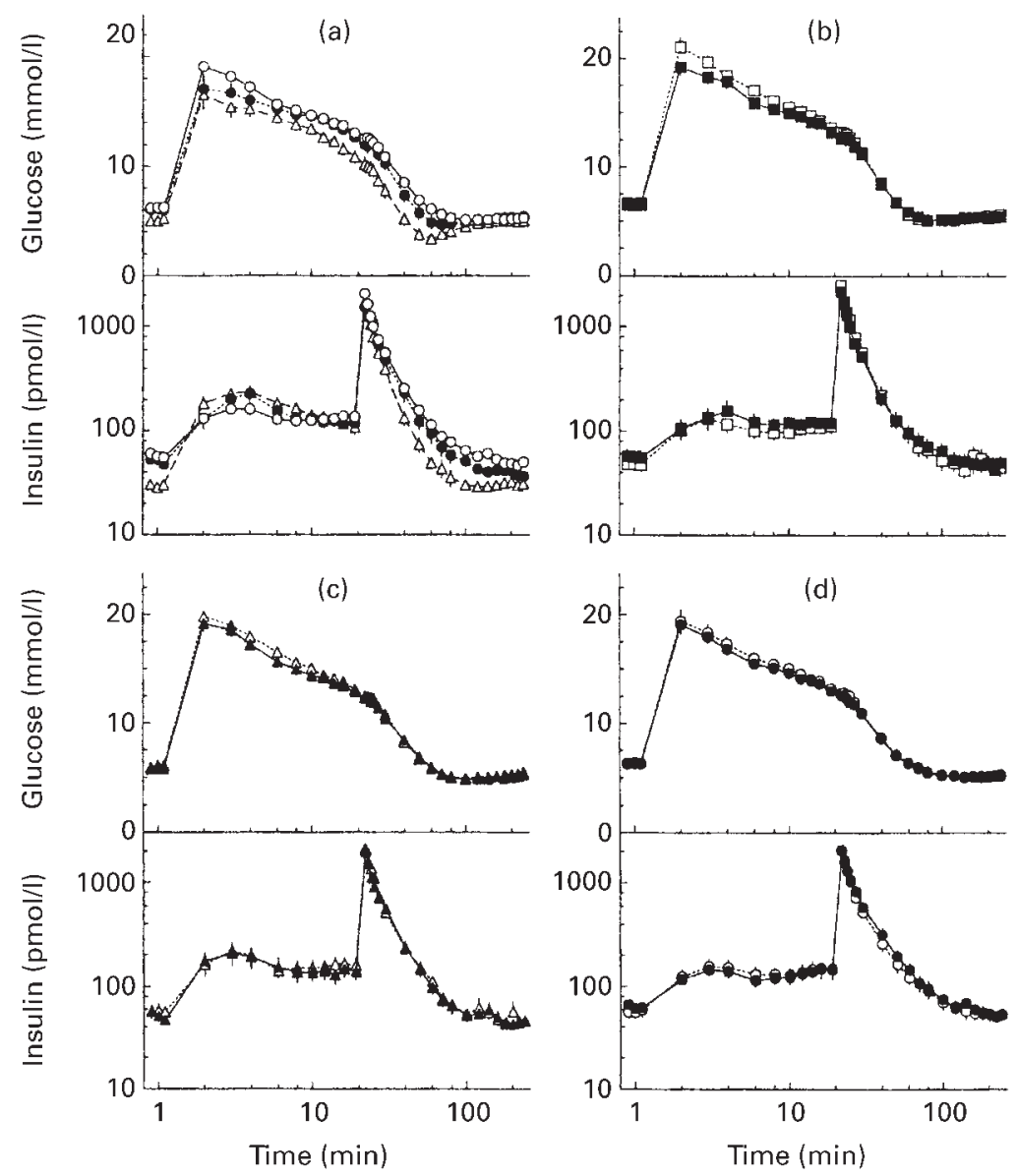

Fig. 1. Plasma glucose and insulin concentrations during the frequently sampled intravenous glucose tolerance test. (a), Values in thirty-four subjects with impaired glucose tolerance $(\bigcirc)$, seven obese controls $(\bullet)$ and eight lean controls $(\Delta)$; (b), values before $(\square)$ and after $(\square)$ 4-months treatment with the high-carbohydratehigh-glycaemic index diet; (c), values before $(\boldsymbol{\Lambda})$ and after $(\Delta)$ 4-months treatment with the low-carbohydrate-high-monounsaturated fat diet; (d), values before ( $\bullet$ ) and after $(O)$ 4-months treatment with the high-carbohydrate-low-glycaemic index diet. Values are means with their standard errors represented by vertical bars.

Table 2. Comparison of subjects in the three diet groups at baseline ${ }^{*} \dagger$

(Mean values and standard errors of the mean)

\begin{tabular}{|c|c|c|c|c|c|c|}
\hline \multirow[t]{2}{*}{ Diet... } & \multicolumn{2}{|c|}{ High-GI } & \multicolumn{2}{|c|}{ Low-Gl } & \multicolumn{2}{|c|}{ MUFA } \\
\hline & Mean & SEM & Mean & SEM & Mean & SEM \\
\hline$n:$ Total & \multirow{2}{*}{\multicolumn{2}{|c|}{$\begin{array}{c}11 \\
2.9\end{array}$}} & \multirow{2}{*}{\multicolumn{2}{|c|}{$\begin{array}{c}13 \\
3: 10\end{array}$}} & \multirow{2}{*}{\multicolumn{2}{|c|}{$\begin{array}{c}11 \\
2: 9\end{array}$}} \\
\hline Men:women & & & & & & \\
\hline Age (years) & $58 \cdot 8$ & 4.0 & $55 \cdot 2$ & $3 \cdot 0$ & $55 \cdot 8$ & 4.0 \\
\hline $\mathrm{BMl}\left(\mathrm{kg} / \mathrm{m}^{2}\right)$ & $29 \cdot 3$ & $2 \cdot 2$ & $29 \cdot 7$ & $1 \cdot 2$ & $30 \cdot 6$ & 1.7 \\
\hline Fasting glucose (mmol/l) & $5 \cdot 35$ & 0.28 & $5 \cdot 22$ & 0.27 & 4.73 & 0.24 \\
\hline Glycated haemoglobin (\%) & 5.95 & 0.18 & $5 \cdot 67$ & $0 \cdot 15$ & 5.42 & 0.27 \\
\hline Systolic blood pressure $(\mathrm{mmHg})$ & 126 & 6 & 129 & 4 & 126 & 6 \\
\hline Diastolic blood pressure (mmHg) & 78 & 3 & 80 & 2 & 76 & 2 \\
\hline $\mathrm{S}_{1}\left(10^{-5} /(\min \times \mathrm{pmol} / \mathrm{I})\right)$ & $5 \cdot 61$ & 0.89 & 4.47 & 0.95 & $5 \cdot 56$ & 0.78 \\
\hline$S_{G}\left(10^{-2} / \mathrm{min}\right)$ & $1 \cdot 7$ & 0.2 & 1.7 & 0.2 & 1.7 & 0.1 \\
\hline $\operatorname{AIR}_{\mathrm{glu}}\left(10^{2} \times \mathrm{pmol} / \mathrm{I} \times 10 \mathrm{~min}\right)$ & 6.02 & $2 \cdot 07$ & $5 \cdot 13$ & $1 \cdot 25$ & $9 \cdot 84$ & $2 \cdot 70$ \\
\hline DI $(/ 10)$ & 0.29 & 0.12 & 0.22 & 0.08 & 0.48 & $0 \cdot 11$ \\
\hline
\end{tabular}

High-GI, high-carbohydrate-high-glycaemic index diet; low-Gl, high-carbohydrate-low-glycaemic index diet; MUFA, low-carbohydrate-high-monounsaturated fat diet; $\mathrm{S}_{\text {I, }}$, insulin sensitivity index; $\mathrm{S}_{\mathrm{G}}$, glucose effectiveness; $A I R_{\text {glu, }}$, pancreatic responsivity area under the insulin response curve for $10 \mathrm{~min}$ after intravenous glucose; DI, glucose disposition index.

* For details of diets see p. 478.

$\dagger$ None of the differences was statistically significant. 
Table 3. Nutrient intakes at baseline and during the study* (Mean values and standard errors of the mean)

\begin{tabular}{|c|c|c|c|c|c|c|c|c|}
\hline \multirow[t]{2}{*}{ Diet... } & & \multicolumn{2}{|c|}{ High-GI } & \multicolumn{2}{|c|}{ Low-GI } & \multicolumn{2}{|c|}{ MUFA } & \multirow[b]{2}{*}{$P+$} \\
\hline & & Mean & SEM & Mean & SEM & Mean & SEM & \\
\hline \multirow[t]{2}{*}{ Energy (MJ): } & Baseline & $7 \cdot 32$ & 0.28 & $7 \cdot 78$ & 0.50 & 6.99 & 0.49 & \\
\hline & Study & $7 \cdot 17$ & 0.39 & 7.09 & 0.28 & 7.86 & 0.55 & 0.028 \\
\hline \multirow[t]{2}{*}{ Protein (\% energy): } & Baseline & $17 \cdot 4^{\mathrm{bc}}$ & 0.8 & $18 \cdot 7^{\mathrm{ab}}$ & 0.5 & $17.9^{\mathrm{abc}}$ & 1.0 & \\
\hline & Study & $17 \cdot 4^{\mathrm{bc}}$ & 0.7 & $19 \cdot 4^{\mathrm{a}}$ & 0.5 & $16 \cdot 4^{c}$ & 0.5 & 0.027 \\
\hline \multirow{2}{*}{ Total fat (\% energy): } & Baseline & $30 \cdot 0^{\mathrm{b}}$ & $2 \cdot 2$ & $29 \cdot 8^{\mathrm{b}}$ & 1.8 & $30 \cdot 2^{\mathrm{b}}$ & 2.5 & \\
\hline & Study & $27.9^{b c}$ & 1.9 & $24 \cdot 7^{c}$ & 1.6 & $35 \cdot 4^{a}$ & 1.5 & $<0.001$ \\
\hline \multirow[t]{2}{*}{ Saturated fat (\% energy): } & Baseline & $9 \cdot 3$ & 1.0 & $9 \cdot 7$ & 0.6 & $9 \cdot 6$ & 1.0 & \\
\hline & Study & 8.9 & 0.8 & $7 \cdot 8$ & 0.7 & $9 \cdot 3$ & 0.7 & NS \\
\hline \multirow[t]{2}{*}{ Monounsaturated fat (\% energy): } & Baseline & $11.9^{b}$ & 0.9 & $11 \cdot 7^{b}$ & 0.7 & $12 \cdot 2^{b}$ & $1 \cdot 2$ & \\
\hline & Study & $10 \cdot 8^{\mathrm{bc}}$ & 0.8 & $9 \cdot 2^{\mathrm{c}}$ & 0.6 & $18 \cdot 1^{\mathrm{a}}$ & 0.8 & $<0.001$ \\
\hline \multirow{2}{*}{ Polyunsaturated fat (\% energy): } & Baseline & $6 \cdot 0$ & 0.5 & $6 \cdot 1$ & 0.7 & 5.9 & 0.5 & \\
\hline & Study & $5 \cdot 2$ & 0.4 & 4.9 & 0.4 & 5.5 & 0.3 & NS \\
\hline \multirow{2}{*}{ Cholesterol (mg): } & Baseline & 215 & 27 & 247 & 34 & 209 & 25 & \\
\hline & Study & 207 & 23 & 195 & 18 & 204 & 18 & NS \\
\hline \multirow[t]{2}{*}{ Ethanol (\% energy): } & Baseline & $1 \cdot 3$ & 0.7 & 1.4 & 0.6 & 0.5 & 0.2 & \\
\hline & Study & 1.7 & 0.7 & 1.0 & 0.4 & 0.7 & $0 . \overline{3}$ & NS \\
\hline \multirow[t]{2}{*}{ Carbohydrate (\% energy): } & Baseline & $51 \cdot 2^{\mathrm{abc}}$ & $2 \cdot 6$ & $50 \cdot 0^{\mathrm{bc}}$ & $2 \cdot 1$ & $51 \cdot 3^{\mathrm{abc}}$ & $2 \cdot 4$ & \\
\hline & Study & $52 \cdot 8^{\mathrm{ab}}$ & 2.0 & $54 \cdot 8^{a}$ & 1.7 & $47 \cdot 4^{\mathrm{C}}$ & $1 \cdot 7$ & 0.001 \\
\hline \multirow[t]{2}{*}{ Dietary fibre $(\mathrm{g})$ : } & Baseline & $24 \cdot 1^{b}$ & $2 \cdot 0$ & $24 \cdot 2^{b}$ & 1.5 & $21 \cdot 9^{b}$ & 1.9 & \\
\hline & Study & $22 \cdot 7^{\mathrm{b}}$ & $2 \cdot 2$ & $36 \cdot 2^{a}$ & $2 \cdot 6$ & $23 \cdot 7^{b}$ & $2 \cdot 1$ & $<0.001$ \\
\hline \multirow[t]{2}{*}{ Glycaemic index: } & Baseline & $58 \cdot 7^{\mathrm{b}}$ & 0.7 & $58 \cdot 7^{b}$ & 0.6 & $58 \cdot 8^{b}$ & 0.8 & \\
\hline & Study & $59 \cdot 3^{b}$ & 0.6 & $54 \cdot 4^{\mathrm{a}}$ & 0.7 & $58 \cdot 6^{\mathrm{b}}$ & 0.4 & $<0.001$ \\
\hline \multirow[t]{2}{*}{ Glycaemic load: } & Baseline & $93.5^{\mathrm{ab}}$ & 4.9 & $91 \cdot 1^{\mathrm{b}}$ & 3.6 & $93.2^{\mathrm{ab}}$ & 3.9 & \\
\hline & Study & $96 \cdot 8^{a}$ & 3.5 & $91 \cdot 8^{\mathrm{ab}}$ & $2 \cdot 6$ & $88 \cdot 3^{\mathrm{b}}$ & 3.4 & 0.032 \\
\hline
\end{tabular}

High-GI, high-carbohydrate-high-glycaemic index diet; low-GI, high-carbohydrate-low-glycaemic index diet; MUFA, low-carbohydrate-high-monounsaturated fat diet.

${ }^{\mathrm{a}, \mathrm{b}, \mathrm{c}}$ Mean values within a row with unlike superscript letters were significantly different $(P \leq 0.05)$.

${ }^{*}$ For details of diets and procedures, see p. 478.

† Significance of interaction between diet and time ANOVA. There was no significant main effect of diet or time for any nutrient.

rise on MUFA. Individual changes in body weight did not relate to changes in recorded energy intake ( $r$ 0.09, $P=0.59)$.

Diastolic blood pressure tended to increase over the first 8 weeks on all three diets (Fig. 3(b)). Over the last 8 weeks diastolic blood pressure remained stable on MUFA and high-GI but fell significantly on low-GI by $8 \mathrm{mmHg}$. The change in diastolic blood pressure at 16 weeks on lowGI, -3.6 (SEM 1.1) $\mathrm{mmHg}$, differed significantly from changes on low-GI and MUFA at 8 weeks, high GI at 12 weeks, and MUFA at 16 weeks. Changes in systolic blood pressure followed the same trends, but were not statistically significant.

Fasting glucose tended to rise less on low-GI than highGI or MUFA, but the difference was not significant (Fig. 3(c)). Compared with the change on high-GI, $\mathrm{HbA}_{1 \mathrm{c}}$ increased significantly on MUFA, and decreased non-significantly on low-GI (Fig. 3(d)). Changes in serum total and LDL-cholesterol or triacylglycerol did not differ significantly among dietary treatments (Fig. 4). However, compared with high-GI, HDL-cholesterol decreased significantly on low-GI, with no significant difference on MUFA (Fig. 4). NEFA tended to decrease from baseline, but the differences among diets were not significant (high-GI, - 0.037 (SEM 0.046) mEq/l; low-GI, -0.188 (SEM 0.116) mEq/l; MUFA, -0.144 (SEM 0.068) $\mathrm{mEq} / \mathrm{l})$.

The plasma glucose and insulin during the FSIGTT for the three treatment groups are shown on Fig. 1. For each
FSIGTT test, a fractional SD (FSD) was derived for the estimate of $S_{I}$ as a measure of the goodness of fit of the data points to the kinetic model $(\mathrm{FSD}=\mathrm{SD}$ of estimate expressed as a $\%$ of the value for $\mathrm{S}_{\mathrm{I}}$ ). The median value of FSD for the seventy FSIGTT tests in the IGT subjects was $3.15 \%$, with $71 \%$ of the values being $\leq 5 \%$. In the control subjects, the median FSD was $2 \cdot 3 \% . \mathrm{S}_{\mathrm{I}}$ and $\mathrm{AIR}_{\mathrm{glu}}$ tended to improve from baseline on the low-GI diet and to deteriorate on high-GI and MUFA (Figs. 5 and 6), but the differences were not significant. Relative to baseline, mean DI increased by $56 \%$ on low-GI and decreased by $16 \%$ on MUFA, with no change on highGI. After adjusting for baseline values, the increase in DI on low-GI was significantly different from the changes on both MUFA and high-GI (Fig. 5). Changes in DI were not significantly related to individual changes in body weight, nor to recorded energy, carbohydrate or monounsaturated fat intakes, or glycaemic load. The correlation between change in DI and diet GI during treatment was not quite significant $(r-0.31 ; P=0.070)$ but became significant when adjusted for carbohydrate intake as $\%$ of energy $(r-0.34 ; P=0 \cdot 044)$.

\section{Discussion}

A low dietary glycaemic load is associated with a reduced risk of developing type 2 diabetes (Salmerón et al. $1997 a, b)$ and is considered desirable in the dietary management of insulin resistance because it reduces postprandial 


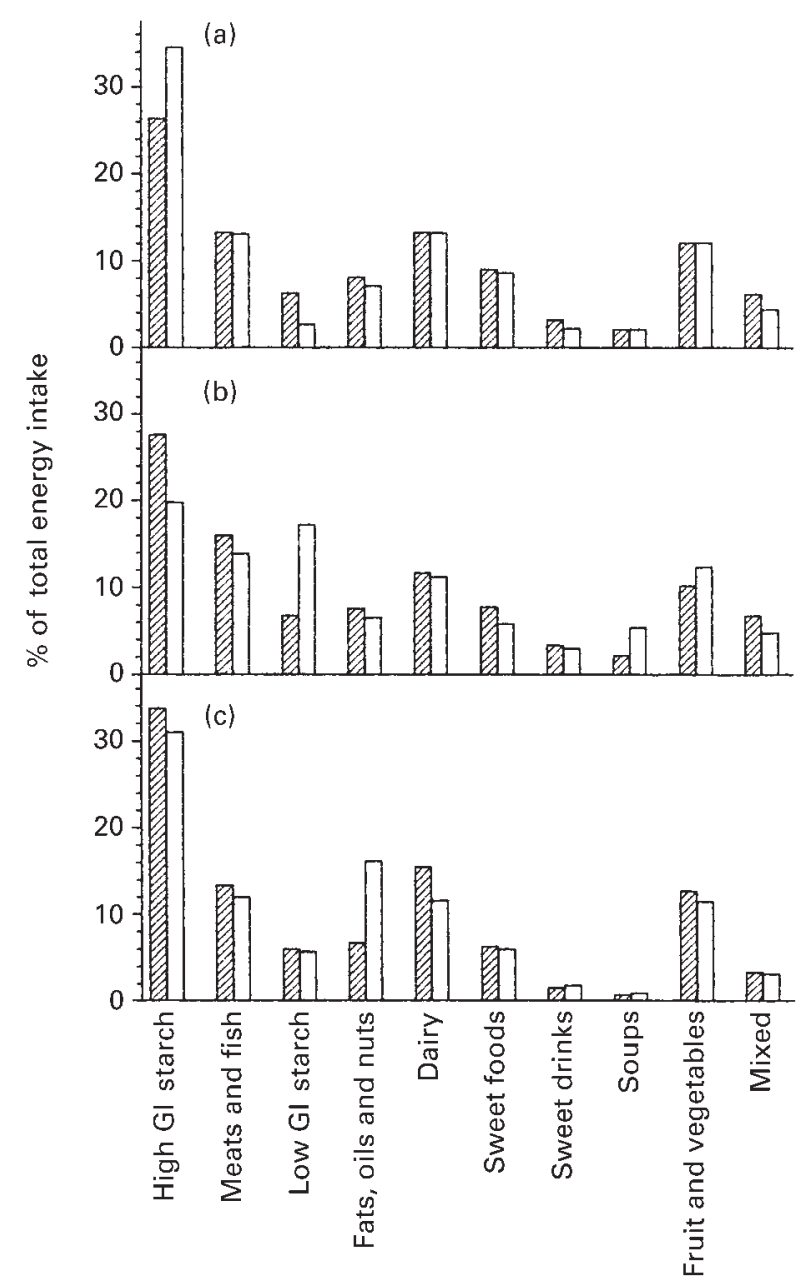

Fig. 2. Percentage of total energy derived from foods in the food groups shown along the $x$ axis for subjects on the high-carbohydratehigh-glycaemic index diet (a); high-carbohydrate-low-glycaemic index diet (b); or the low-carbohydrate-high-monounsaturated fat diet (c). (四), Baseline intakes; ( $\square$ ), intakes during the study.

plasma insulin (Jeppesen et al. 1997; Reaven, 1997). Reducing postprandial insulin may be beneficial because a vicious cycle may exist in which insulin resistance and high plasma insulin exacerbate each other (Kahn et al. 1993; Del Prato et al. 1994). However, there are two different ways of reducing dietary glycaemic load: reducing carbohydrate intake, or reducing diet GI. Our results show that these two manoeuvres do not have the same effects in subjects with IGT: reducing diet GI improved $\mathrm{HbA}_{1 \mathrm{c}}$, diastolic blood pressure and glucose DI compared with reducing carbohydrate intake.

DI can be considered an index of the ability of the $\beta$-cell to compensate for changes in insulin sensitivity by increasing insulin secretion, with a low value indicating reduced $\beta$-cell responsiveness (Chen et al. 1988). Although there is a wide range of $S_{I}$ and $A_{I R}$ glu in the normal population, the product of $\mathrm{S}_{\mathrm{I}} \times \mathrm{AIR}_{\mathrm{glu}}$ (i.e. DI) tends to be constant (Kahn et al. 1993; Clausen et al. 1996). We found that DI improved significantly by over $50 \%$ on low-GI relative to both the MUFA and high-GI. Since defects in both insulin sensitivity and $\beta$-cell responsiveness are required for type 2 diabetes to develop (Ferrannini, 1998; Gerich, 1998), a treatment associated with sustained improvement in $\beta$-cell responsiveness would be expected to reduce conversion from IGT to diabetes. Indeed, in Pima Indians who converted from IGT to diabetes, DI fell by $48 \%$ (Weyer et al. 1999). Thus, improved DI could explain why a low diet GI was associated with reduced risk of developing type 2 diabetes in both the Nurses' Health (Salmerón et al. 1997b) and Health Professionals Follow-up Studies (Salmerón et al. 1997a).

The low-GI diet was associated with increased $\beta$-cell responsiveness in the absence of a change in insulin resistance. Since hyperinsulinaemia may promote the atherosclerotic process (Stout, 1990), it can be asked whether increased $\beta$-cell responsiveness may have a deleterious long-term effect on cardiovascular disease risk by increasing plasma insulin. The answer is not known, but we do not believe this to be a strong possibility. Increased $\beta$-cell responsiveness means that more insulin is secreted for a given change in plasma glucose concentration; it does not necessarily imply an increase in plasma insulin. Indeed, Swinburn et al. (1991) showed that a high-carbohydrate diet improved $\beta$-cell responsiveness with no change in insulin sensitivity and that this was associated with a reduction in mean plasma insulin, presumably due to a simultaneously reduced plasma glucose. The results of the UK Prospective Diabetes Study provide evidence that raising plasma insulin does not promote cardiovascular disease, at least in subjects with diabetes. Treatment of type 2 diabetes with insulin or sulfonylurea had similar effects on glycaemic control, but increased plasma insulin significantly compared with the use of metformin. Despite an increase in plasma insulin, the reduction in the risk of developing cardiovascular complications in subjects treated with insulin or sulfonylurea was virtually identical to that in subjects treated with metformin (UK Prospective Diabetes Study Group, 1998).

The high-GI diet contained typical North American foods and is similar to diets used in studies that failed to show any effect of high carbohydrate intake on insulin sensitivity (Borkman et al. 1991; Swinburn et al. 1991; Garg et al. 1992; Hughs et al. 1995). The present results are consistent with this in that high-GI had no effect on insulin sensitivity, pancreatic responsiveness or DI compared with MUFA.

One of the main arguments against a high-carbohydrate diet for insulin-resistant subjects is that it enhances cardiovascular disease risk because of increased serum triacylglycerol and reduced HDL (Garg et al. 1994; Jeppesen et al. 1997). Studies showing these effects are typically 3-6 weeks long and employ metabolically controlled diets with carbohydrate intake increased from 40 to $60 \%$ of energy. Several features of our study design could explain why we saw no effect on triacylglycerol and a trend toward increased HDL on high-GI relative to MUFA. The 16-week study period may have missed transient changes in lipids (Parks \& Hellerstein, 2000). Schaefer et al. (1995) have suggested that high-carbohydrate diets may not adversely affect blood lipids in ad-libitum situations because the small amount of weight lost may offset the deleterious effects on blood lipids seen when the diets are given on 

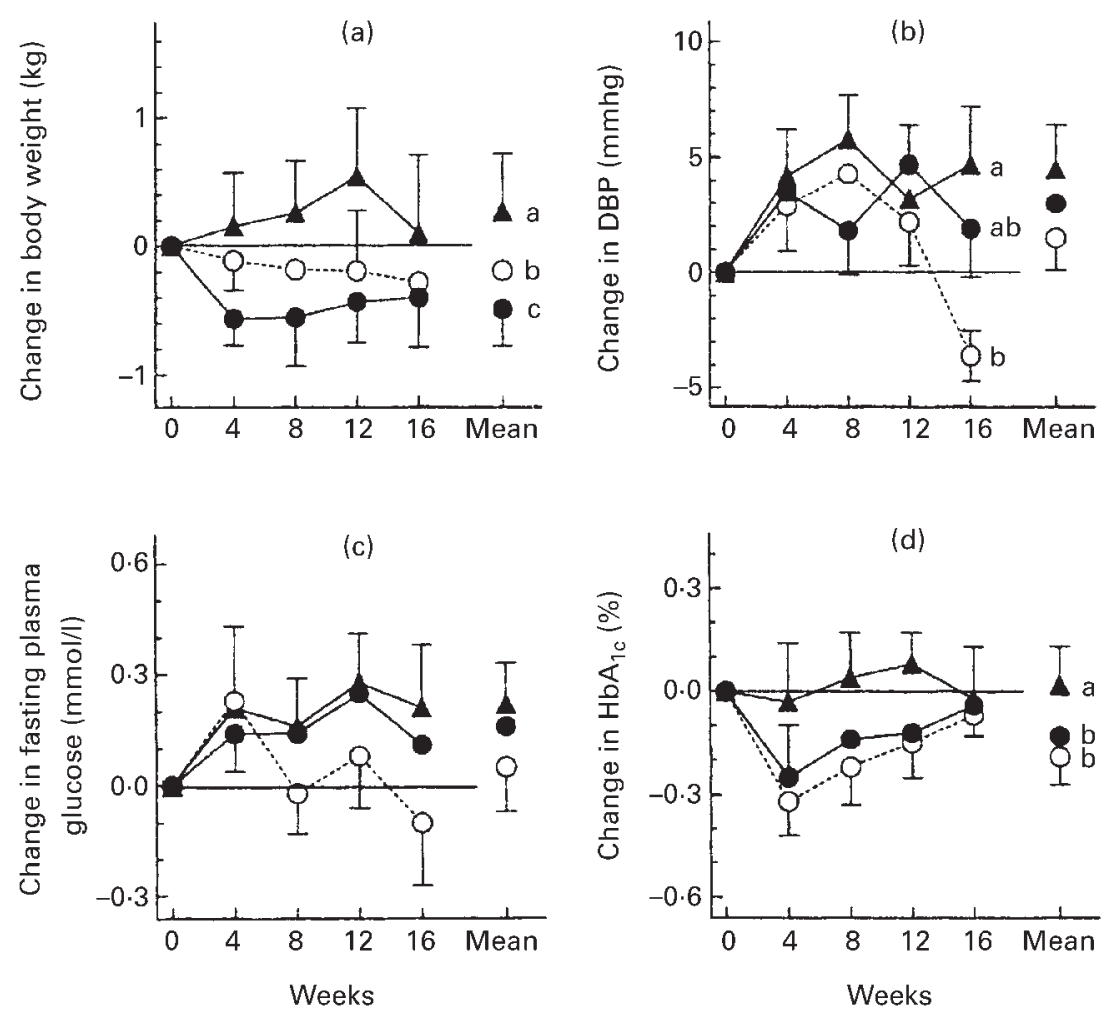

Fig. 3. Changes in body weight (a); diastolic blood pressure (DBP) (b); fasting plasma glucose (c); and glycated haemoglobin $\left(\mathrm{HbA}_{1 \mathrm{c}}\right)$ (d) during the 4-month treatment with the high-carbohydrate-high-glycaemic index $(\bullet)$, high-carbohydrate-low-glycaemic index, low-carbohydrate-high monounsaturated fat $(\mathbf{\Lambda})$ diets. Mean represents the mean of the changes at 1, 2, 3 and 4 months. Values are means with their standard errors represented by vertical bars. ${ }^{a, b, c}$ Mean values with unlike superscript letters were significantly different $(P<0.05)$.

an iso-energetic basis. This is consistent with our results in which there was about $0.75 \mathrm{~kg}$ weight loss on high-GI relative to MUFA. Furthermore, the 5-7\% increase in carbohydrate intake may have been too small to have an effect on triacylglycerol and HDL (Parks \& Hellerstein, 2000).

The small, but statistically significant, differences in body weight change between the three dietary treatment groups may have confounded some of the effects observed, but we do not believe they can account for the changes in DI. Despite the significant difference in weight change between the high-GI and MUFA diets, there was no difference in $\mathrm{S}_{\mathrm{I}}, \mathrm{AIR}_{\mathrm{glu}}$ or DI. In addition, after adjusting for baseline values, DI increased significantly on low-GI compared with high-GI, despite statistically significantly less weight loss on low-GI.

Strictly speaking, the present study compared different types of dietary advice. One strength of this approach is that the results obtained are directly applicable to clinical practice since they were attained with diets self-selected by the subjects over a 4-month period. The weaknesses include the facts that the dietary changes were relatively small and we cannot be sure what the subjects actually ate. These weaknesses would have the effect of reducing the magnitude of expected differences in outcomes between dietary treatments, and reducing the power to detect them. Despite this, significant differences in outcome were obtained.
It is well-known that self-reported energy intake is inaccurate, especially among obese subjects who underestimate their true intakes (Heymsfield et al. 1995). However, there is evidence that reported percentage nutrient intakes are fairly reliable (Lissner \& Lindroos, 1994). The significant diet $\times$ time interaction for recorded energy intake probably represents reporting error rather than a true difference. If $1570 \mathrm{~kJ} / \mathrm{d}$ more energy really was consumed on MUFA than low-GI, $>5 \mathrm{~kg}$ weight would have been gained; however, the observed weight difference was only $0.4 \mathrm{~kg}$. Daily walking for $1 \mathrm{~h}$ would be required to expend $1570 \mathrm{~kJ} / \mathrm{d}$ with no change in weight, an amount of activity that would probably improve insulin sensitivity (Despres \& Lamarche, 1994), and is not consistent with the effects we observed on MUFA. Lack of correlation between changes in recorded energy intake and changes in weight, and lack of difference in blood lipids also argue against any significant difference in energy intake in the three diet groups.

Slowing carbohydrate absorption by pharmacological inhibition of carbohydrate digestive enzymes reduces postprandial insulin and improves insulin sensitivity in subjects with IGT (Chiasson et al. 1996). Also, a low-GI diet has been shown to improve insulin sensitivity measured in vitro in adipocytes and in vivo using a short insulin tolerance test in subjects at risk of cardiovascular disease (Frost et al. 1998). We were unable to show a significant effect of a low-GI diet on insulin sensitivity. Differences 

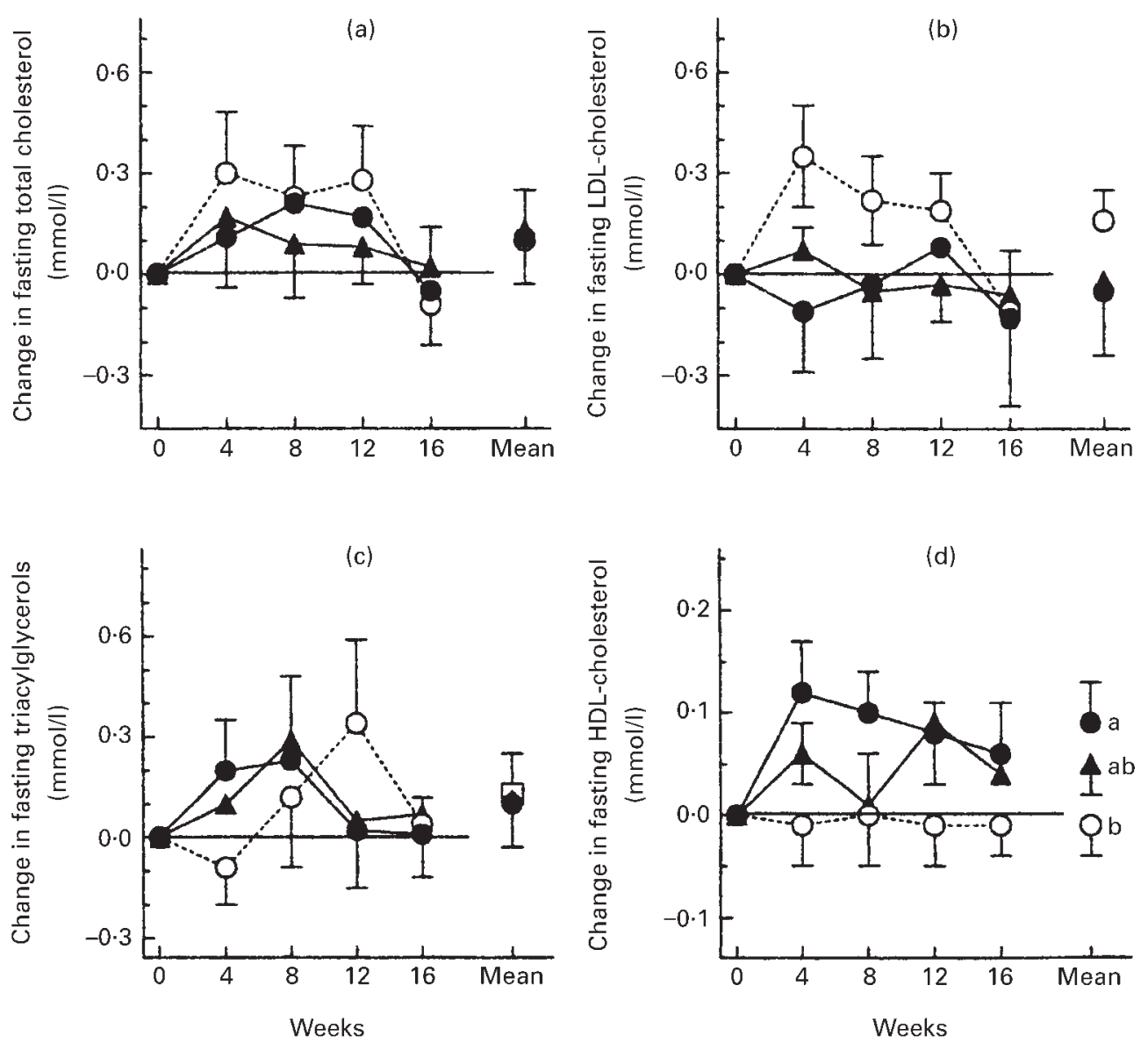

Fig. 4. Changes in fasting total cholesterol (a), LDL-cholesterol (b), triacylglycerols (c) and HDL-cholesterol (d) during the 4-month treatment with the high-carbohydrate-high glycaemic index $(\bullet)$, high-carbohydrate-low-glycaemic index $(\bigcirc)$ or low-carbohydrate-high monounsaturated fat $(\boldsymbol{\Lambda})$ diets. Mean represents the mean of the changes at 1, 2, 3 and 4 months. Values are means with their standard errors represented by vertical bars. ${ }^{a, b}$ Mean values with unlike superscript letters were significantly different $(P<0.05)$.

in the methods of measuring insulin sensitivity, differences in the populations studied, and lack of statistical power may account for the discrepant results. The power of the present study to detect the observed difference in insulin sensitivity was only about $50 \%$. It was lower than expected not because the effect-size was small but because the variation was high. Based on repeated-measures ANOVA, the within-subject variation in $S_{I}$ was estimated to be $27 \%$ of the mean, about twice the value of $14.4 \%$ expected from the literature (Ferrari et al. 1991). The values for FSD were acceptably low showing that experimental errors in the estimation of $S_{I}$ cannot account for the high variation. This suggests that the within-subject variation of the FSIGTT is greater in IGT subjects than normal. In addition, the IGT subjects we studied were quite heterogeneous; in about $67 \%$ of them, low insulin sensitivity was the predominant defect, while in about $33 \%$ low pancreatic responsiveness was more important.

Recently, changes in insulin secretion and sensitivity in Pima Indians whose glucose tolerance deteriorated from normal to IGT to diabetes over a 5 year period were compared with those in individuals who remained normal (Weyer et al. 1999). Progression from IGT to diabetes was accompanied by a $19 \%$ reduction in insulin sensitivity when measured at high plasma insulin $(>13000 \mathrm{pmol} / \mathrm{l})$. However, when measured at a physiological plasma insulin concentration $(840 \mathrm{pmol} / \mathrm{l})$ there was no significant change in insulin sensitivity associated with progression from IGT to diabetes (Weyer et al. 1999). Our inability to detect differences in insulin sensitivity may be related to the relatively low mean peak insulin achieved during the FSIGTT test $(1000 \mathrm{pmol} / \mathrm{l}$ at $22 \mathrm{~min}$ declining to $<800 \mathrm{pmol} / \mathrm{l}$ at $23 \mathrm{~min}$ ). Furthermore, improving insulin sensitivity may be less important than maintaining insulin secretion for subjects with IGT, since the main factor associated with conversion from IGT to diabetes was a $51 \%$ decrease in insulin secretion (Weyer et al. 1999).

We conclude that the long-term effects of altering source of dietary carbohydrate differ from those of altering amount of carbohydrate. High-carbohydrate-low-GI dietary advice may have beneficial effects on $\beta$-cell function in subjects with IGT, and may, therefore, be useful for the dietary management of IGT.

\section{Acknowledgements}

This study was supported by the Canadian Diabetes Association and the International Olive Oil Council. 

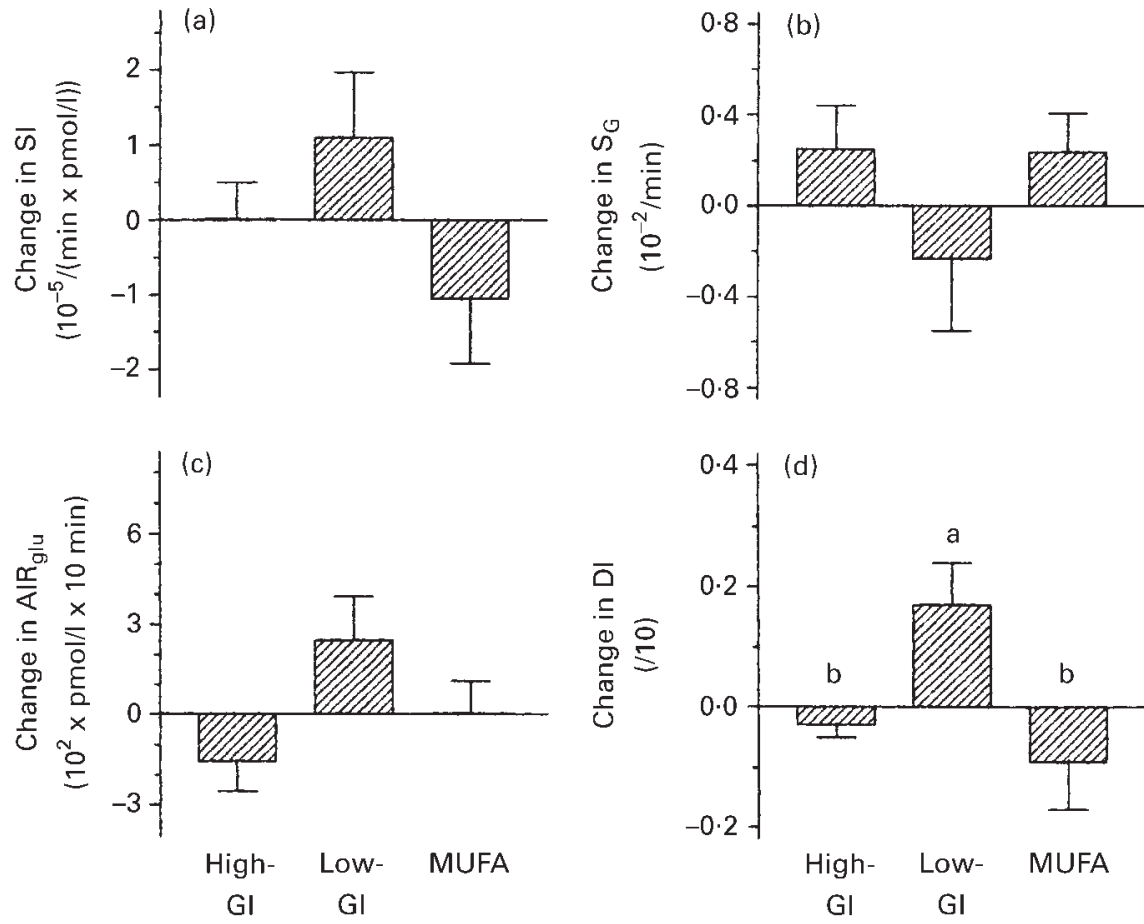

Fig. 5. Changes in insulin sensitivity $(\mathrm{SI} ; \mathrm{a})$, glucose effectiveness $\left(\mathrm{S}_{\mathrm{G}} ; \mathrm{b}\right)$, pancreatic responsivity $\left(\mathrm{AlR}_{\mathrm{glu}} ; \mathrm{c}\right)$ and glucose disposition index $(\mathrm{DI}$; d) after 4-months treatment with the high-carbohydrate-low-glycaemic index (high-Gl), high-carbohydrate-low-glycaemic index (low-Gl) or low-carbohydrate-high-monounsaturated fat (MUFA) diets. The changes have been adjusted for baseline, and the total length of each $y$ axis is 2 times the mean baseline value. Values are means with their standard errors represented by vertical bars. ${ }^{\mathrm{a}, \mathrm{b}}$ Mean values with unlike superscript letters were significantly different $(P<0.05)$.

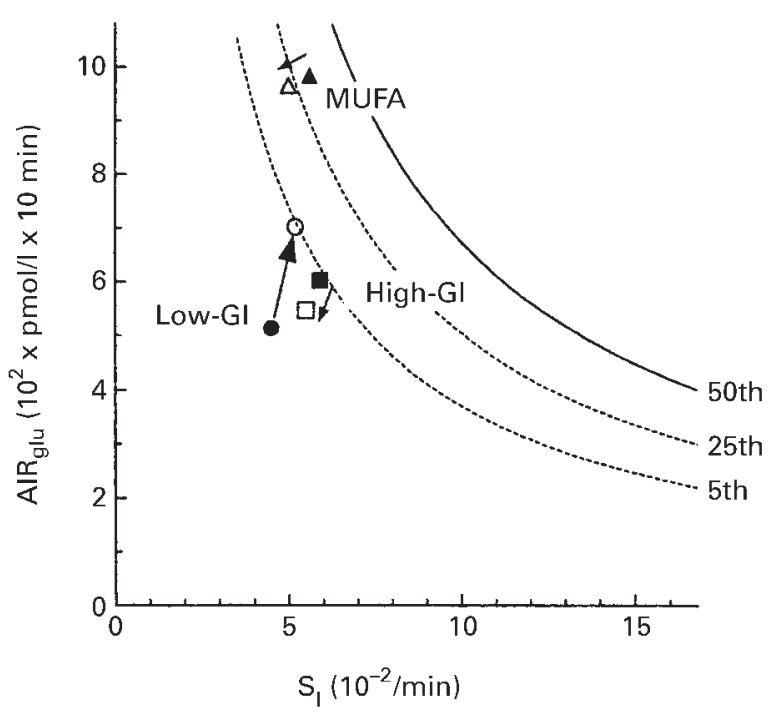

Fig. 6. Changes in pancreatic responsivity $\left(A I R_{\text {glu }}\right)$ relative to changes in insulin sensitivity $\left(S_{\mid}\right)$in impaired glucose-tolerant subjects before ( $\square$ ) and after ( $\square$ ) high-carbohydrate-high-glycaemic index (high-Gl; $n$ 11); before $(\bullet)$ and after $(O)$ high-carbohydratelow-glycaemic index (low-Gl; $n$ 13) and before $(\mathbf{\Delta})$ and after $(\Delta)$ low-carbohydrate-high-monounsaturated fat (MUFA; $n$ 11) diets for 4 months. The lines represent the prediction line (50th percentile) and the 25th and 5th percentiles of the regression between $\mathrm{AIR}_{\mathrm{glu}}$ and $S_{1}$ derived from the fifteen control subjects.

\section{References}

American Diabetes Association (1997) Report of the Expert Committee on the Diagnosis and Classification of Diabetes Mellitus. Diabetes Care 20, 1183-1197.

Balkau B, Shipley M, Jarrett RJ, Pyörälä L, Pyörälä M, Forhan A \& Eschwège E (1998) High blood glucose concentration is a risk factor for mortality in middle-aged nondiabetic men: 20year follow-up in the Whitehall Study, the Paris Prospective Study, and the Helskinki Policemen Study. Diabetes Care 21, 360-367.

Boden G, Chen X, Ruiz J, White JV \& Rossetti L (1994) Mechanisms of fatty acid-induced inhibition of glucose uptake. Journal of Clinical Investigation 93, 2438-2446.

Borkman M, Campbell LV, Chisholm DJ \& Storlien LH (1991) Comparison of the effects on insulin sensitivity of high carbohydrate and high fat diets in normal subjects. Journal of Clinical Endocrinology and Metabolism 72, 432-437.

Carpentier A, Mittelman SD, Lamarche B, Bergman RN, Giacca A \& Lewis GF (1999) Acute enhancement of insulin secretion by FFA in humans is lost with prolonged FFA elevation. American Journal of Physiology 276, E1055-E1066.

Chen M, Bergman RN \& Porte D Jr (1988) Insulin resistance and $\beta$-cell dysfunction in aging: the importance of dietary carbohydrate. Journal of Clinical Endocrinology and Metabolism 67, 951-957.

Chew I, Brand JC, Thorburn AW \& Truswell AS (1988) Application of the glycemic index to mixed meals. American Journal of Clinical Nutrition 47, 53-56. 
Chiasson JL, Josse RG, Leiter LA, Mihic M, Nathan DM, Palmason C, Cohen RM \& Wolever TMS (1996) The effect of acarbose on insulin sensitivity in subjects with impaired glucose tolerance. Diabetes Care 19, 1190-1193.

Clausen JO, Borch-Johnsen K, Ibsen H, Bergman RN, Hougaard P, Winther K \& Pedersen O (1996) Insulin sensitivity index, acute insulin response, and glucose effectiveness in a population-based sample of 380 young healthy caucasians: analysis of the impact of gender, body fat, physical fitness and life-style factors. Journal of Clinical Investigation 98, 1195-1209.

Del Prato S, Leonetti F, Simonson DC, Sheehan P, Matsuda M \& DeFronzo RA (1994) Effect of sustained physiologic hyperinsulinaemia and hyperglycaemia on insulin secretion and insulin sensitivity in man. Diabetologia 37, 1025-1035.

Despres JP \& Lamarche B (1994) Low-intensity endurance exercise training, plasma lipoproteins and the risk of coronary heart disease. Journal of Internal Medicine 236, 7-22.

Ferrannini E (1998) Insulin resistance versus insulin deficiency in non-insulin-dependent diabetes mellitus: problems and prospects. Endocrine Reviews 19, 477-490.

Ferrari P, Alleman Y, Shaw S, Riesen W \& Weidmann P (1991) Reproducibility of insulin sensitivity measured by the minimal model method. Diabetologia 34, 527-530.

Finegood DT, Hramiak IM \& Duprè J (1990) A modified protocol for estimation of insulin sensitivity with the minimal model of glucose kinetics in patients with insulin-dependent diabetes. Journal of Clinical Endocrinology and Metabolism 70, $1538-1549$.

Food and Agricultural Organization of the United Nations (1998) Report of a Joint FAO/WHO Expert Consultation: Carbohydrates in Human Nutrition. FAO Food and Nutrition Paper no. 66. Rome: FAO.

Frost G, Leeds A, Trew G, Margara R \& Dornhorst A (1998) Insulin sensitivity in women at risk of coronary heart disease and the effect of a low glycemic index diet. Metabolism 47, $1245-1251$

Garg A, Bantle JP, Henry RR, Coulston AM, Griver KA, Raatz SK, Brinkley L, Chen YDI, Grundy SM, Huet BA \& Reaven GM (1994) Effects of varying carbohydrate content of diet in patients with non-insulin-dependent diabetes mellitus. Journal of the American Medical Association 271, 1421-1428.

Garg A, Grundy SM \& Unger RH (1992) Comparison of effects of high and low carbohydrate diets on plasma lipoproteins and insulin sensitivity in patients with mild NIDDM. Diabetes 41, $1278-1285$.

Gerich JE (1998) The genetic basis of type 2 diabetes mellitus: impaired insulin secretion versus impaired insulin sensitivity. Endocrine Reviews 19, 491-503.

Gordon DJ \& Rifkind BM (1989) High-density lipoprotein - the clinical implications of recent studies. New England Journal of Medicine 321, 1311-1316.

Heymsfield SB, Darby PC, Muhlheim LS, Gallagher D, Wolper C \& Allison DB (1995) The calorie: myth, measurement. and reality. American Journal of Clinical Nutrition 62, Suppl., $1034 \mathrm{~S}-1041 \mathrm{~S}$.

Hokanson JE \& Austin MA (1996) Plasma triglyceride level is a risk factor for cardiovascular disease independent of high-density lipoprotein cholesterol level: a meta-analysis of population-based prospective studies. Journal of Cardiovascular Risk 3, 213-219.

Hughs VA, Fiatarone MA, Fielding RA, Ferrara CM, Elahi D \& Evans WJ (1995) Long-term effects of a high carbohydrate diet and exercise on insulin action in older subjects with impaired glucose tolerance. American Journal of Clinical Nutrition 62 , 426-433.

Indar-Brown K, Norenberg C \& Madar Z (1992) Glycemic and insulinemic responses after ingestion of ethnic foods by
NIDDM and healthy subjects. American Journal of Clinical Nutrition 55, 89-95.

Jenkins DJA, Ghafari H, Wolever TMS, Taylor RH, Barker HM, Fielden H, Jenkins AL \& Bowling AC (1982) Relationship between the rate of digestion of foods and postprandial glycaemia. Diabetologia 22, 450-455.

Jeppesen J, Schaaf P, Jones C, Zhou M-Y, Chen Y-DI \& Reaven GM (1997) Effects of low-fat, high-carbohydrate diets on risk factors for ischemic heart disease in postmenopausal women. American Journal of Clinical Nutrition 65, 1027-1033.

Kahn SE, Prigeon RL, McCulloch DK, Boyko EJ, Bergman RN, Schwartz MW, Neifing JL, Ward WK, Beard JC, Palmer JP \& Porte D Jr (1993) Quantification of the relationship between insulin sensitivity and $\beta$-cell function in human subjects: evidence for a hyperbolic function. Diabetes 42, 1663-1672.

Lissner L \& Lindroos A-K (1994) Is dietary underreporting macronutrient-specific? European Journal of Clinical Nutrition 48, 453-454.

Luscombe ND, Noakes M \& Clifton PM (1999) Diets high and low in glycemic index versus high monounsaturated fat diets: effects on glucose and lipid metabolism in NIDDM. European Journal of Clinical Nutrition 53, 473-478.

Pacini G \& Bergman RN (1986) MINMOD:.A computer program to calculate insulin sensitivity and pancreatic responsivity from the frequently sampled intravenous glucose tolerance test. Computer Methods and Programs in Biomedicine 23, 113-122.

Parks EJ \& Hellerstein MK (2000) Carbohydrate-induced hypertriacylglycerolemia: historical perspective and review of biological mechanisms. American Journal of Clinical Nutrition 71, 412-433.

Reaven GM (1995) Pathophysiology of insulin resistance in human disease. Physiological Reviews 75, 473-486.

Reaven GM (1997) Do high carbohydrate diets prevent the development or attenuate the manifestations (or both) of syndrome $\mathrm{X}$ ? A viewpoint strongly against. Current Opinion in Lipidology 8, 23-27.

Salmerón J, Ascherio A, Rimm EB, Colditz GA, Spiegelman D, Jenkins DJ, Stampfer MJ, Wing AL \& Willett WC (1997a) Dietary fiber, glycemic load, and risk of NIDDM in men. Diabetes Care 20, 545-550.

Salmerón J, Manson JE, Stampfer MJ, Colditz GA, Wing AL \& Willett WC (1997b) Dietary fiber, glycemic load and risk of non-insulin-dependent diabetes mellitus in women. Journal of the American Medical Association 277, 472-477.

Schaefer EJ, Lichtenstein AH, Lamon-Fava S, McNamara JR, Schaefer MM, Rasmussen H \& Ordovas JM (1995) Body weight and low-density lipoprotein cholesterol changes after consumption of a low-fat ad libitum diet. Journal of the American Medical Association 274, 1450-1455.

Stout RW (1990) Insulin and atheroma: 20-yr perspective. Diabetes Care 13, 631-654.

Swinburn BA, Boyce VL, Bergman RN, Howard BV \& Bogardus C (1991) Deterioration in carbohydate metabolism and lipoprotein changes induced by modern, high fat diet in Pima Indians and Caucasians. Journal of Clinical Endocrinology and Metabolism 73, 156-165.

UK Prospective Diabetes Study Group (1998) Intensive bloodglucose control with sulfonylureas or insulin compared with conventional treatment and risk of complications in patients with type 2 diabetes (UKPDS 33). Lancet 352, 837-853.

US Department of Agriculture (1990) Dietary Guidelines for Americans, third ed. DHHS publication no. 273-930. Washington, DC: U.S. Govt. Printing Office.

Weyer C, Bogardus C, Mott DM \& Pratley RE (1999) The natural history of insulin secretory dysfunction and insulin resistance in the pathogenesis of type 2 diabetes mellitus. Journal of Clinical Investigation 104, 787-794. 
Wolever TMS, Bentum-Williams A \& Jenkins DJA (1995) Physiologic modulation of plasma FFA concentrations by diet: metabolic implications in non-diabetic subjects. Diabetes Care 18, 962-970.

Wolever TMS, Jenkins DJA, Collier GR, Lee R, Wong GS \& Josse RG (1988) Metabolic response to test meals containing different carbohydrate foods: 1 . relationship between rate of digestion and plasma insulin response. Nutrition Research 8, 573-581.

Wolever TMS, Jenkins DJA, Jenkins AL \& Josse RG (1991) The glycemic index: methodology and clinical implications. American Journal of Clinical Nutrition 54, 846-854.

World Health Organization (1980) WHO Expert Committee on Diabetes Mellitus. Second Report. pp. 8-14. Technical Report Series no. 646. Geneva: World Health Organization.

Zhou Y-P \& Grill VE (1994) Long-term exposure of rat pancreatic islets to fatty acids inhibits glucose-induced insulin secretion and biosynthesis through a glucose fatty acid cycle. Journal of Clinical Investigation 93, 870-876. 